\title{
Effect of driving pressure on mortality in ARDS patients during lung protective mechanical ventilation in two randomized controlled trials
}

Claude Guérin ${ }^{1,2,3^{*}}$, Laurent Papazian ${ }^{4,5,6}$, Jean Reignier ${ }^{7}$, Louis Ayzac ${ }^{8}$, Anderson Loundou ${ }^{5}$, Jean-Marie Forel ${ }^{9}$ and on behalf of the investigators of the Acurasys and Proseva trials

\begin{abstract}
Background: Driving pressure ( $\Delta \mathrm{Prs})$ across the respiratory system is suggested as the strongest predictor of hospital mortality in patients with acute respiratory distress syndrome (ARDS). We wonder whether this result is related to the range of tidal volume $\left(\mathrm{V}_{T}\right)$. Therefore, we investigated $\Delta$ Prs in two trials in which strict lungprotective mechanical ventilation was applied in ARDS. Our working hypothesis was that $\Delta$ Prs is a risk factor for mortality just like compliance (Crs) or plateau pressure (Pplat,rs) of the respiratory system.

Methods: We performed secondary analysis of data from 787 ARDS patients enrolled in two independent randomized controlled trials evaluating distinct adjunctive techniques while they were ventilated as in the low $V_{T}$ arm of the ARDSnet trial. For this study, we used $V_{T}$, positive end-expiratory pressure (PEEP), Pplat,rs, $\mathrm{Crs}, \Delta \mathrm{Prs}$, and respiratory rate recorded 24 hours after randomization, and compared them between survivors and nonsurvivors at day 90. Patients were followed for 90 days after inclusion. Cox proportional hazard modeling was used for mortality at day 90 . If colinearity between $\Delta$ Prs, Crs, and Pplat,rs was verified, specific Cox models were used for each of them.
\end{abstract}

Results: Both trials enrolled 805 patients of whom 787 had day-1 data available, and 533 of these survived. In the univariate analysis, $\Delta$ Prs averaged $13.7 \pm 3.7$ and $12.8 \pm 3.7 \mathrm{cmH}_{2} \mathrm{O}(P=0.002)$ in nonsurvivors and survivors, respectively. Colinearity between $\Delta$ Prs, Crs and Pplat,rs, which was expected as these variables are mathematically coupled, was statistically significant. Hazard ratios from the Cox models for day-90 mortality were $1.05(1.02-1.08)(P=0.005), 1.05$ $(1.01-1.08)(P=0.008)$ and $0.985(0.972-0.985)(P=0.029)$ for $\Delta P r s$, Pplat,rs and $C r s$, respectively. PEEP and $V_{T}$ were not associated with death in any model.

Conclusions: When ventilating patients with low $V_{T}, \Delta$ Prs is a risk factor for death in ARDS patients, as is Pplat,rs or Crs. As our data originated from trials from which most ARDS patients were excluded due to strict inclusion and exclusion criteria, these findings must be validated in independent observational studies in patients ventilated with a lung protective strategy.

Trial registration: Clinicaltrials.gov NCT00299650. Registered 6 March 2006 for the Acurasys trial. Clinicaltrials.gov NCT00527813. Registered 10 September 2007 for the Proseva trial.

Keywords: ARDS, Prone position, Neuromuscular blocking agents, Driving pressure, Compliance, Plateau pressure, Lung protective ventilation

\footnotetext{
* Correspondence: claude.guerin@chu-lyon.fr

${ }^{1}$ Réanimation Médicale Groupement Hospitalier Nord Hospices civils de Lyon, Lyon, France

Université de Lyon, 1 69100, Villeurbanne, France

Full list of author information is available at the end of the article
} 


\section{Background}

Lung protective ventilation, which is a current strong recommendation in patients with the acute respiratory distress syndrome (ARDS), includes several components, the most important of them being lowering tidal volume $\left(\mathrm{V}_{\mathrm{T}}\right)$ and limiting plateau (Pplat,rs) equal to or below $30 \mathrm{~cm} \mathrm{H} \mathrm{H}_{2} \mathrm{O}$. This combined strategy is indeed the single ventilator intervention that has been shown to significantly improve survival so far [1]. This trial introduced scaling of $\mathrm{V}_{\mathrm{T}}$ to the predicted body weight. However, in the lower $V_{T}$ group with the significant improvement in survival, $\mathrm{V}_{\mathrm{T}}$ was not strictly set to $6 \mathrm{ml} / \mathrm{kg}$ but may have been accommodated in the range $4-8 \mathrm{ml} / \mathrm{kg}$. $\mathrm{V}_{\mathrm{T}}$ is equal to the difference between plateau (Pplat,rs) and total positive end-expiratory pressure (PEEPtot,rs) measured at zero flow divided by the compliance of the respiratory system (Crs). The difference between Pplat,rs and PEEPtot,rs is the driving pressure $(\Delta \mathrm{Prs})$. Therefore, using $\Delta$ Prs to select $\mathrm{V}_{\mathrm{T}}$ is equivalent to titrating $\mathrm{V}_{\mathrm{T}}$ for $\mathrm{Crs}$, as $\mathrm{V}_{\mathrm{T}}$ is equal to $\Delta$ Prs divided by Crs.

The first report suggesting that $\Delta$ Prs is associated with mortality came from the study by Amato et al. [2] Recently a retrospective analysis of several trials in patients with ARDS comparing different PEEP levels at the same $V_{T}$ or different $V_{T}$ levels at the same PEEP, or a combination of both, found that $\Delta$ Prs is the stronger predictor of mortality as compared with Pplat,rs [3]. Furthermore, the relative risk of mortality significantly increased above a threshold in the vicinity of $15 \mathrm{~cm}$ $\mathrm{H}_{2} \mathrm{O}$. It is important to emphasize at this point that the threshold of a driving pressure of 14 or $15 \mathrm{cmH}_{2} \mathrm{O}$ to predict outcome or titrate $\mathrm{V}_{\mathrm{T}}$ has not been validated or confirmed. With the aim of attempting to confirm this finding, we also wondered whether this result may be due to the wide range of $\mathrm{V}_{\mathrm{T}}$ used across the trials included. To try to answer this question, we investigated $\Delta$ Prs from two trials $[4,5]$ in which strict lungprotective mechanical ventilation, in particular $6 \mathrm{ml} / \mathrm{kg}$ predicted body weight $\mathrm{V}_{\mathrm{T}}$, was applied to patients with ARDS. Our working hypothesis was that $\triangle$ Prs was associated with death, just like compliance (Crs) or Pplat,rs.

\section{Methods}

This is a secondary analysis of patients enrolled in two previously published randomized controlled trials, namely Acurasys [4] and Proseva [5]. The first trial compared the neuromuscular blocking agent (NMBA) cisatracurium to placebo and the second compared the prone to the supine position. Both had similar inclusion criteria (notably early ARDS and partial pressure of oxygen in arterial blood $\left(\mathrm{PaO}_{2}\right)$ /oxygen fraction in air $\left(\mathrm{F}_{\mathrm{I}} \mathrm{O}_{2}\right)<150 \mathrm{~mm} \mathrm{Hg}$ under PEEP $\left.\geq 5 \mathrm{~cm} \mathrm{H} \mathrm{H}_{2} \mathrm{O}\right)$ and similar lung-protective mechanical ventilation (in particular $6 \mathrm{ml} / \mathrm{kg}$ predicted body weight $\mathrm{V}_{\mathrm{T}}$, limited Pplat,rs and
$\mathrm{PEEP} / \mathrm{F}_{\mathrm{I}} \mathrm{O}_{2}$ table [1]). ARDS was identified based on the American-European consensus definition criteria [6]. Both trials identified significant survival benefit in the experimental group.

From the case report form of each original trial, we extracted the relevant variables for the present study, namely sequential organ failure assessment (SOFA) score, continuous NMBA infusion, prone position, $\mathrm{pH}$, partial pressure of carbon dioxide in arterial blood $\left(\mathrm{PaCO}_{2}\right), \mathrm{PaO}_{2} / \mathrm{F}_{\mathrm{I}} \mathrm{O}_{2}$, lactate, respiratory rate, $\mathrm{V}_{\mathrm{T}}$, PEEP, Pplat,rs, Crs and $\Delta$ Prs, which were recorded at day 1 as the values corresponding to those gathered 24 hours after randomization in each trial. In addition, we used gender, age and simplified acute physiology score (SAPS) II recorded at the time of admission and compared between survivors and nonsurvivors at day 90. The allocation assignment in the two trials was entered as predefined covariates into the models. Furthermore, as recent experimental data suggest that the amount of energy transferred from the ventilator into the lung may be a contributing factor to ventilator-induced lung injury (VILI) [7], we computed the mechanical power as $\Delta \operatorname{Prs} \times$ $\mathrm{V}_{\mathrm{T}} \times$ respiratory rate. It was expressed as $\mathrm{J} / \mathrm{min}$ and was included in the analysis in the present study.

Descriptive statistics included percentages for categorical variables and means and standard deviation (SD) for continuous variables and were compared using nonparametric tests. Cox proportional hazard models were used with covariates significantly different between survivors and non survivors at the threshold of 0.20 and mortality at day 90 as the dependent variable. Even though $\Delta$ Prs, Crs, and Pplat,rs are mathematically coupled, we planned to formally test the collinearity within them and, if verified, to use a specific Cox model for each. Because $\mathrm{pH}$ and lactate interact, we used their interaction term in the Cox models. We also included those collinear variables two-by-two into four additional Cox regression models, besides the other covariates. One model pertained to Pplat,rs and $\Delta$ Prs, one to Crs and $\Delta$ Prs, one to $\Delta$ Prs and mechanical power, and one to Crs and Pplat,rs. Two interpretations of the results could a priori be deciphered. If both variables in the couple lacked significance, the conclusion could be that the same information was carried by each component of the couple. If one of the variables in the couple remained significantly correlated with survival, this variable would be more informative than the other in the couple. Univariate and multivariate Cox proportional hazard regression models were used to estimate the hazard ratio (HR).

Kaplan-Meier graphs were used to express the probability of death from inclusion to day 90 and were compared across groups by the log rank test. Groups were defined from the median values in the present cohort. 
We split $\Delta$ Prs into five quintiles of almost 150 patients each following the method used in both the Amato [3] and the Lung Safe [8] studies by using the Ntiles function in SPSS software. Comparison between quintiles was made by analysis of variance (ANOVA) with posthoc comparison from the first quintile performed using the Tukey test. A $p$ value $<0.05$ was considered significant. The statistical analysis was conducted using IBM SPSS Statistics, version 20.0 (IBM SPSS Inc., Chicago, IL, USA).

\section{Results}

A total of 805 patients were included in the two trials, of these patient, 787 had data available at day 1 . There were 533 survivors and 254 non-survivors at day 90 (mortality rate $32.3 \%$ for the combined trials). The comparison between survivors and non survivors at day 90 is shown in Table 1.

As the collinearity between $\Delta$ Prs, mechanical power, Pplat,rs and Crs was statistically significant, a Cox model was constructed for each of these variables. The Cox model pertaining to $\Delta$ Prs is shown in Table 2. Age, SOFA, prone position, $\mathrm{pH}$, lactate, $\mathrm{pH}$ and its interaction with lactate and $\triangle$ Prs were significantly associated with the outcome at day 90 whilst NMBA was not. For each of the additional three Cox models that included mechanical power, Pplat,rs, or Crs as a single covariable, the significant predictors of patient outcome were the same as for $\Delta \operatorname{Prs}$ (see additional files 1,2 and 3). The HR was high for lactate in each Cox model, with wide confidence intervals (Table 2 and Additional files 1, 2 and 3). After multiple adjustments of coupled variables, four additional Cox models were performed (Additional file 4). $\Delta$ Prs and Pplat,rs remained significantly associated with patient outcome, meaning that each of them brought specific and distinct information (model 1 in Additional file 4). For $\Delta$ Prs and mechanical power, $\Delta$ Prs maintained a significant association with mortality at day 90 , and hence carries specific information (model 2 in Additional file 4). However, for $\Delta \mathrm{Prs}$ and $\mathrm{Crs}$, and for Pplat,rs and Crs (models 3 and 4, respectively, in Additional file 4), neither of the variables in each pair were statistically significant. Therefore, it could be concluded that $\Delta \operatorname{Prs}$ and $\mathrm{Crs}$, on one hand, and Pplat,rs and Crs on the other hand, share the same information.

Figure 1 displays the unadjusted mortality rates at day 90 across five quintiles of $\Delta$ Prs (Fig. 1a), mechanical power (Fig. 1b), Pplat,rs (Fig. 1c) and Crs (Fig. 1d). No distinct threshold of $\Delta$ Prs was identified (Fig. 1).

Table 1 Characteristics at the time of inclusion or day 1 between survivors and non-survivors at day 90

\begin{tabular}{|c|c|c|c|c|}
\hline Variables & All $(n=787)$ & Survivors $(n=533)$ & Nonsurvivors $(n=254)$ & $P$ \\
\hline Male gender & $542(68.9)$ & $366(68.7)$ & $176(69.3)$ & 0.923 \\
\hline Age, years & $59 \pm 16$ & $56 \pm 15$ & $66 \pm 14$ & $<0.001$ \\
\hline SAPS II on ICU admission & $45 \pm 15$ & $45 \pm 16$ & $51 \pm 15$ & $<0.001$ \\
\hline SOFA score on day 1 & $7 \pm 4$ & $7 \pm 4$ & $9 \pm 4$ & $<0.001$ \\
\hline Continuous NMBA as allocation group & $173(22.0)$ & $117(22.0)$ & $56(22.0)$ & 0.976 \\
\hline Prone position as allocation group & $233(34.4)$ & $181(34.0)$ & $52(20.5)$ & $<0.001$ \\
\hline Arterial pH on day 1 & $7.35 \pm 0.09$ & $7.36 \pm 0.08$ & $7.32 \pm 0.10$ & $<0.001$ \\
\hline $\mathrm{PaCO}_{2}$ on day $1, \mathrm{mmHg}$ & $47 \pm 11$ & $46 \pm 11$ & $47 \pm 11$ & 0.076 \\
\hline $\mathrm{PaO}_{2} / \mathrm{FIO}_{2}$ ratio on day 1 & $159 \pm 74$ & $163 \pm 76$ & $152 \pm 68$ & 0.056 \\
\hline Lactate on day $1, \mathrm{mmol} / \mathrm{L}$ & $2.0 \pm 1.9$ & $1.8 \pm 1.6$ & $2.4 \pm 2.2$ & $<0.001$ \\
\hline Respiratory rate on day $1, /$ minute & $27 \pm 6$ & $26 \pm 5$ & $27 \pm 6$ & 0.010 \\
\hline Tidal volume on day $1, \mathrm{ml}$ & $397 \pm 76$ & $398 \pm 76$ & $395 \pm 78$ & 0.413 \\
\hline Tidal volume on day $1, \mathrm{ml} / \mathrm{PBW} \mathrm{kg}$ & $6.3 \pm 0.8$ & $6.2 \pm 0.8$ & $6.3 \pm 0.8$ & 0.691 \\
\hline PEEP on day $1, \mathrm{~cm} \mathrm{H} 2 \mathrm{O}$ & $10 \pm 3$ & $10 \pm 3$ & $10 \pm 3$ & 0.210 \\
\hline Plateau pressure on day $1, \mathrm{~cm} \mathrm{H}_{2} \mathrm{O}$ & $23 \pm 4$ & $23 \pm 4$ & $24 \pm 4$ & $<0.001$ \\
\hline Tidal compliance on day $1, \mathrm{ml} / \mathrm{cm} \mathrm{H}_{2} \mathrm{O}$ & $33 \pm 12$ & $34 \pm 12$ & $31 \pm 12$ & 0.016 \\
\hline Driving pressure on day $1, \mathrm{~cm} \mathrm{H}_{2} \mathrm{O}$ & $13 \pm 4$ & $13 \pm 4$ & $14 \pm 4$ & 0.002 \\
\hline Mechanical power on day $1, \mathrm{~J} / \mathrm{min}$ & $13.4 \pm 5.0$ & $13.0 \pm 4.8$ & $14.3 \pm 5.4$ & $<0.001$ \\
\hline
\end{tabular}

Quantitative values are expressed as mean \pm SD and qualitative values are numbers (percentage of group). Tidal compliance of respiratory system was calculated as the ratio of tidal volume to driving pressure. Driving pressure was calculated as the difference between plateau pressure and applied positive end-expiratory pressure (PEEP). Mechanical power was calculated as the product of driving pressure in Newton ( $\mathrm{cm} \mathrm{H} 2 \mathrm{O} \times 0.098)$, tidal volume and respiratory rate. Day 1 was defined as the 24 hours following the inclusion. ICU intensive care unit, SAPS II simplified acute physiology score II, SOFA sequential organ failure assessment, $\mathrm{PaO}_{2} / \mathrm{FIO}_{2}$ ratio the ratio of the partial pressure of arterial oxygen to the fraction of inspired oxygen, $\mathrm{PaCO}_{2}$ partial pressure of arterial carbon dioxide, PBW predicted body weight, NMBA neuromuscular blocking agent 
Table 2 Multivariate Cox regression analysis for factors including driving pressure at day 1 associated with ARDS mortality at day 90

\begin{tabular}{lll}
\hline Variables & $\begin{array}{l}\text { Hazard ratio (95\% } \\
\text { Cl) }\end{array}$ & $p$ \\
\hline Age, per year & $1.04(1.03-1.05)$ & $<0.001$ \\
SOFA score on day 1, per unit & $1.07(1.03-1.11)$ & $<0.001$ \\
$\begin{array}{l}\text { Continuous NMBA as allocation } \\
\text { group, (reference is yes) }\end{array}$ & $0.64(0.45-0.91)$ & 0.012 \\
$\begin{array}{l}\text { Continuous prone position as } \\
\text { allocation group (reference is yes) }\end{array}$ & $0.68(0.47-0.98)$ & 0.037 \\
Respiratory rate on day 1, per unit & $1.01(0.98-1.03)$ & 0.698 \\
PaO 2 /FiO 2 on day 1, per unit & $1.00(0.99-1.01)$ & 0.831 \\
Arterial pH on day 1, per unit & $0.057(0.009-0.371)$ & 0.003 \\
Lactate on day 1, per unit & $18.44(1.39-244.00)$ & 0.027 \\
Interaction between lactate and arterial pH & $0.67(0.47-0.96)$ & 0.030 \\
on day 1, per unit & & \\
Driving pressure on day 1, per unit & $1.05(1.02-1.08)$ & 0.005 \\
\hline Diving pressure was caculed as the difference betw plated pressure
\end{tabular}

Driving pressure was calculated as the difference between plateau pressure and applied positive end-expiratory pressure (PEEP). Day 1 was defined as the 24 hours following the inclusion. $\mathrm{Cl}$ confidence intervals, SOFA sequential organ failure assessment, NMBA neuromuscular blocking agent, $\mathrm{PaO}_{2} / \mathrm{FIO}_{2}$ ratio of the partial pressure of arterial oxygen to the fraction of inspired oxygen

The Kaplan-Meier graphs describing the probability of survival from inclusion to 90 days for $\Delta$ Prs above or below $13 \mathrm{~cm} \mathrm{H} \mathrm{H}_{2} \mathrm{O}$ and for mechanical power above or below $12 \mathrm{~J} / \mathrm{min}$ at day 1 are shown in Fig. 2 . The survival was significantly higher in patients with $\Delta \operatorname{Prs} \leq 13 \mathrm{~cm} \mathrm{H}_{2} \mathrm{O}$ at day 1 than in those with $\Delta \operatorname{Prs}$ $>13 \mathrm{~cm} \mathrm{H}_{2} \mathrm{O}$ and in patients with mechanical power $\leq 12 \mathrm{~J} / \mathrm{min}$ at day 1 than in those with mechanical power $>12 \mathrm{~J} / \mathrm{min}$. Survival was significantly higher in patients with Pplat,rs $<23 \mathrm{~cm} \mathrm{H}_{2} \mathrm{O}$ than in those with Pplat,rs $\geq 23 \quad \mathrm{~cm} \mathrm{H}_{2} \mathrm{O}$ and higher in patients with $\mathrm{Crs}<31 \mathrm{ml} / \mathrm{cmH}_{2} \mathrm{O}$ than in those with $\mathrm{Crs}$ $\geq 31 \mathrm{ml} / \mathrm{cmH}_{2} \mathrm{O}$ (see Additional file 5).

Whereas the unadjusted probabilities of survival were linearly related to quintiles of $\Delta$ Prs, mechanical power, Pplat,rs, and Crs (Fig. 1), their corresponding adjusted counterparts displayed a threshold in the vicinity of $15 \mathrm{cmH}_{2} \mathrm{O}, 15 \mathrm{~J} / \mathrm{min}, 26 \mathrm{cmH}_{2} \mathrm{O}$, and $26 \mathrm{ml} / \mathrm{cmH}_{2} \mathrm{O}$, respectively (Fig. 3). The adjusted survival curves derived from the Cox regression analysis are shown for $\Delta \mathrm{Prs}$ and mechanical power (see Additional file 6) and for Pplat,rs and Crs (see Additional file 7).

\section{Discussion}

The main findings of the present study in our unique cohort were that: (1) $\Delta$ Prs was significantly associated with patient outcome after controlling for confounding factors, (2) survival was significantly higher in patients with $\Delta \operatorname{Prs} \leq 13 \mathrm{~cm} \mathrm{H}_{2} \mathrm{O}$ at day 1 , (3) survival was significantly higher in patients with mechanical power $\leq 12 \mathrm{~J} / \mathrm{min}$ at day 1 and in patients with Pplat $<23 \mathrm{cmH}_{2} \mathrm{O}$, and (4) the information given by $\Delta$ Prs and $\mathrm{Crs}$ is similar. Our main finding was that with $\mathrm{V}_{\mathrm{T}}$ and Pplat controlled, $\Delta$ Prs brings little more additional information independently on Pplat and Crs.

\section{Driving pressure}

Rather than confirming the results of Amato et al. [3], the present findings disclosed the limitation of the prognostic role of $\Delta$ Prs when Plat,rs, $V_{T}$, and PEEP are strictly controlled and set according to the ARMA trial. However, we found that the HR of $\triangle$ Prs was similar in Amato's study and in the present investigation. In Amato's study, in the Cox analysis $\Delta$ Prs was associated with $41 \%$ increased risk of mortality among the 3080 patients used in the combined analysis [3]. In this study, the authors used a 1-SD increment in $\Delta \operatorname{Prs}$ for calculating $\mathrm{HR}$, which represented $7 \mathrm{cmH}_{2} \mathrm{O}$. Thus, when calculating the HR for $1 \mathrm{cmH}_{2} \mathrm{O}$ increment, this was associated with a HR of 1.049 , which is very close to the present result, as shown in Table 2.

In our study, per each $\mathrm{cm} \mathrm{H}_{2} \mathrm{O}$ increase, $\Delta$ Prs was associated with $5 \%$ increase in the risk of death, which is in the same order of magnitude as Pplat,rs, which was also significantly associated with mortality. PEEP and $V_{T}$ were not significantly associated with mortality in the present cohort, whilst these were associated with a significant $2 \%$ and $3 \%$ increase in mortality per $1 \mathrm{~cm} \mathrm{H}_{2} \mathrm{O}$ and per $1 \mathrm{ml} / \mathrm{kg} \mathrm{PBW}$, respectively, in Amato's study [3]. This can be explained by the narrower range of PEEP and $V_{T}$ used in our cohort. Therefore, in contrast to Amato's study [3] our findings did not identify $\Delta \operatorname{Prs}$ as the strongest predictor of death as compared to $\mathrm{V}_{\mathrm{T}}, \mathrm{Crs}$, and Pplat,rs. To explore this finding further, we used a model-building strategy that consisted of a series of Cox models, which included the collinear variables two-by-two (with their interaction) and these were then compared with the corresponding Cox models that used the collinear variable alone. This strategy showed that $\Delta$ Prs and Pplat,rs each provides different information related to patient outcome. However, interaction between them was present, statistically meaning that the effect of each of them on outcome was dependent on the level of the other. In other words, the effect of one covariate modifies the effect of the other on the outcome. When $\Delta$ Prs and mechanical power were analyzed two-by-two, $\Delta$ Prs remained significant but mechanical power did not. That means that $\Delta$ Prs conveys specific information. When $\Delta \mathrm{Prs}$ and $\mathrm{Crs}$ were analyzed together neither of them remained statistically 

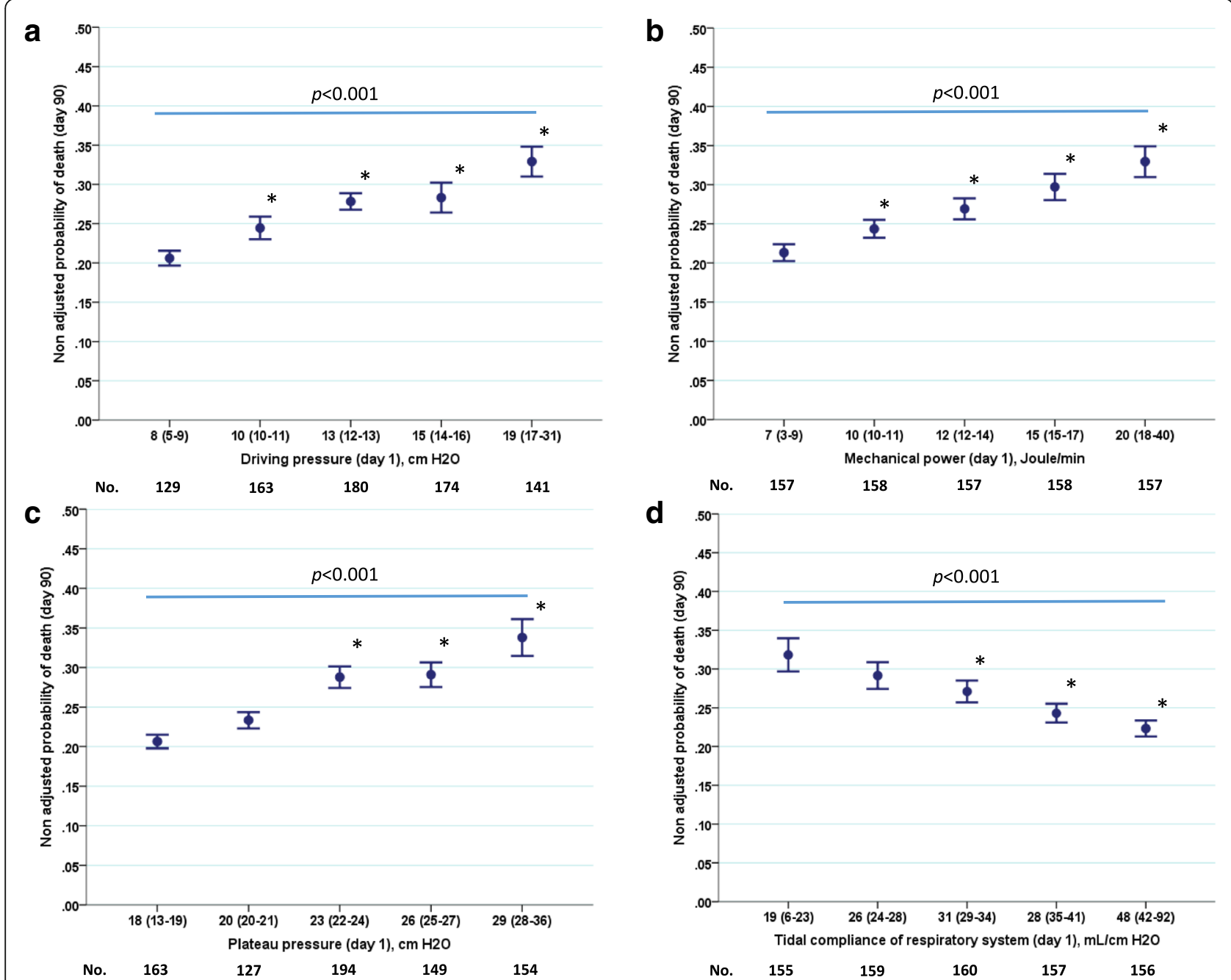

Fig. 1 Unadjusted mortality at day 90 across quintiles of driving pressure (a), mechanical power (bb), Pplat,rs (c) and Crs (d). The bars are standard error of the mean (SEM). The numbers below the $x$ axis are the numbers of patients in each quintile. $P<0.001$ across quintiles (analysis of variance). ${ }^{*} P<0.05$ versus the first quintile

significantly associated with patient outcome. That means that the same information carried by Crs is also carried by $\Delta$ Prs. Both shared the same information. The same result, and hence, the same interpretation also applied for Pplat,rs and Crs.

The Lung Safe study [8] was a prospective international observational investigation in 50 countries, in which data were collected for over 2377 patients with ARDS in the winter season. In 703 of these patients data were available to analyze the rate of mortality at the time of hospital discharge over the range of $\Delta$ Prs and Pplat,rs. The mortality rate increased linearly with increasing $\Delta \operatorname{Prs}$ with no threshold. The slope of the increase in mortality over $\Delta \operatorname{Prs}$ quintiles was steeper than that pertaining to Pplat,rs in the Lung safe study, whereas the slopes were similar in the present study. However, $\mathrm{V}_{\mathrm{T}}$ was not maintained at
$6 \mathrm{ml} / \mathrm{kg}$ in these two studies $[3,8]$ which is at variance with the present study. Furthermore, in the Lung Safe study Pplat,rs was measured in only $40 \%$ of the patients [8], a fact that has been highlighted $[9,10]$.

$\Delta$ Prs ranged between 5 and $31 \mathrm{~cm} \mathrm{H}_{2} \mathrm{O}$ in our cohort (Fig. 1), which is comparable to the range of 7-32 cm $\mathrm{H}_{2} \mathrm{O}$ in the Amato study, but wider than in the Lung Safe study (9-25 $\mathrm{cm} \mathrm{H} \mathrm{H}_{2} \mathrm{O}$ ). It should be stressed that in the Amato study [3] the effect of $\Delta$ Prs was related to the adjusted relative risk of death, whereas in our study, as in the Lung Safe study, the probability of death was analyzed. Moreover only patients with a $\mathrm{P} / \mathrm{F}$ ratio $<150 \mathrm{mmHg}$ were included. $\Delta$ Prs was also reported to be associated with death in a recent large multicenter cohort of patients with ARDS who had acute cor pulmonale [11]. 


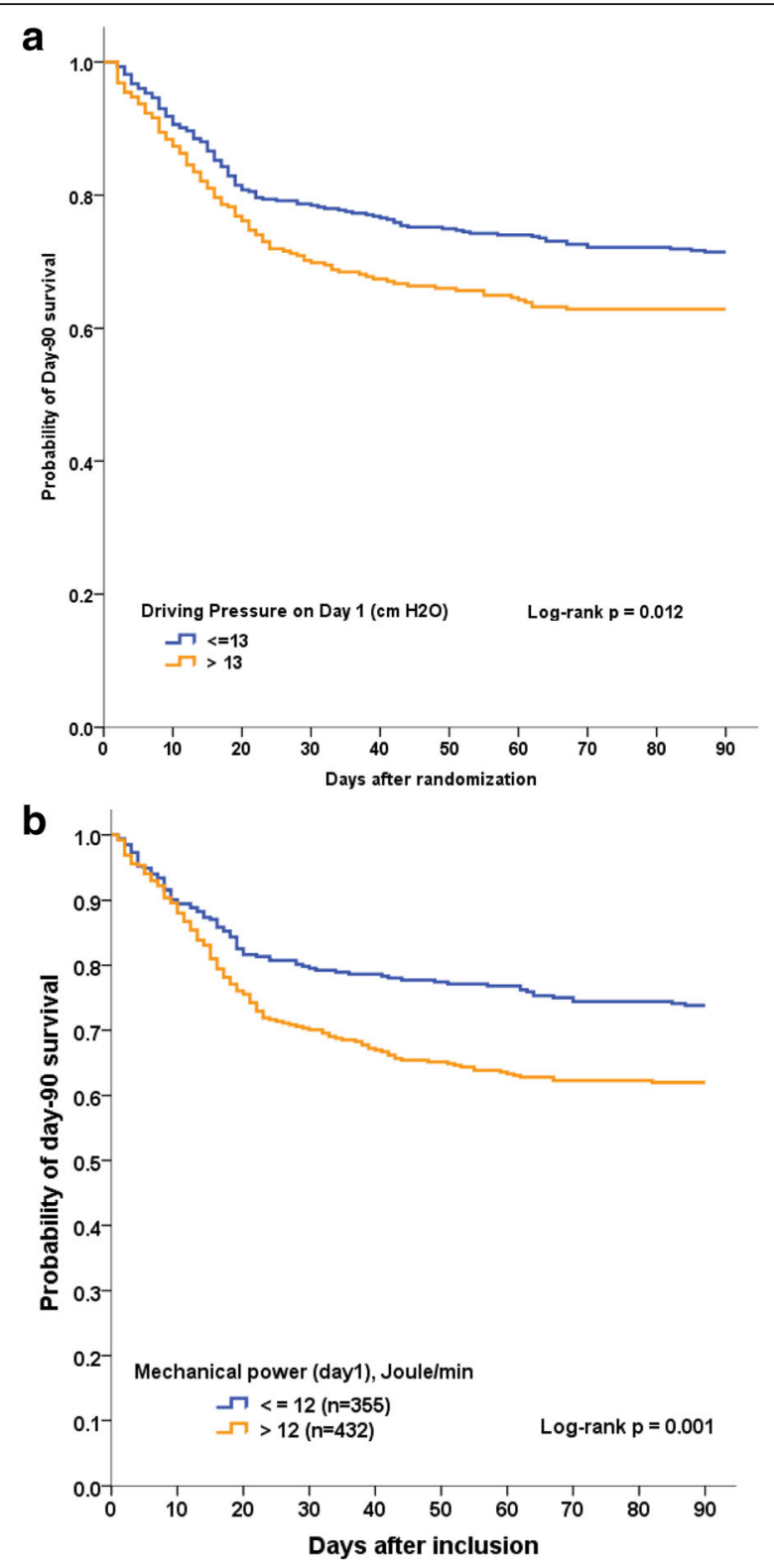

Fig. 2 Kaplan-Meier graphs of the probability of survival for 90 days after inclusion in patients with acute respiratory distress syndrome, according to driving pressure (a) and mechanical power (bb) at day 1. The curves were compared using the log rank test

A more relevant analysis of the data on $\Delta$ Prs would require the knowledge of the transpulmonary $\Delta \mathrm{P}$ $\left(\Delta \mathrm{P}_{\mathrm{L}}\right)$. Talmor et al. found that the reduction in $\Delta \mathrm{P}_{\mathrm{L}}$ was higher in an esophageal pressure-guided group than in a control group, and that $\Delta \mathrm{P}_{\mathrm{L}}$ reduction was higher in survivors than in nonsurvivors, whereas $\Delta$ Prs was similar in both experimental and control groups and in survivors and nonsurvivors [12], confirming that the compliance of the chest wall is a key parameter in interpreting $\Delta \mathrm{Prs}$ and its components.
The role of $\Delta \mathrm{P}_{\mathrm{L}}$ to optimize the use of mechanical ventilation in the prone position should be further investigated, in particular regarding PEEP selection [13], by using a physiological approach [14].

\section{Mechanical power}

The concept that the magnitude of energy transferred from the ventilator into the lung may contribute to VILI has recently arisen and has been confirmed in an experimental study in normal pigs receiving a combination of a large number of $\mathrm{V}_{\mathrm{T}}$ and respiratory rates [15]. In this study mechanical power of $12 \mathrm{~J} / \mathrm{min}$ was found to promote VILI. In the present study, our secondary goal was to explore whether the mechanical power was associated with the outcome. We found that this was the case and the threshold of $12 \mathrm{~J} / \mathrm{min}$ was associated with significant distinct probabilities of survival. Interestingly, the median value of mechanical power in the present cohort was the same as that found experimentally as the threshold above which VILI occurred [15]. We also found that the value of the mechanical power in $\mathrm{J} / \mathrm{min}$ was very close to that of $\Delta \operatorname{Prs}$ in $\mathrm{cm} \mathrm{H}_{2} \mathrm{O}$. The relevance of the present data on mechanical power should be confirmed by further investigations. Should mechanical power be confirmed as a significant independent predictor of survival its computation at the bedside should be recommended. Recently, Gattinoni et al. [16] proposed using the first-order equation to compute mechanical power. Our present approach is much simpler and can be easily implemented at the bedside.

The probability of survival in our study was expressed as unadjusted and adjusted, taking into account the covariates selected by the Cox models. This explains the difference between the data shown in Fig. 1 and Fig. 3 . In the former, a linear relationship was observed between survival and $\Delta$ Prs, mechanical power, Pplat,rs and Crs. This suggests there is no safe dose of mechanical ventilation. However, when the survival was adjusted with covariates, a threshold was disclosed for the survival across quintiles.

\section{Limitations and strengths}

Our study was limited by: (1) the fact that data were collected from two positive trials where survival was markedly affected by the experimental approach subjected to randomization; (2) as in other trials in patients with ARDS, more than $60 \%$ of patients meeting the criteria for ARDS were excluded from enrollment into the trials; and (3) lack of generalizability, as patients with $\mathrm{PaO} 2 / \mathrm{FiO} 2>150 \mathrm{mmHg}$ at 24 hours were excluded from the analysis. However, as discussed previously, our ARDS sample was more homogeneous in terms of the 


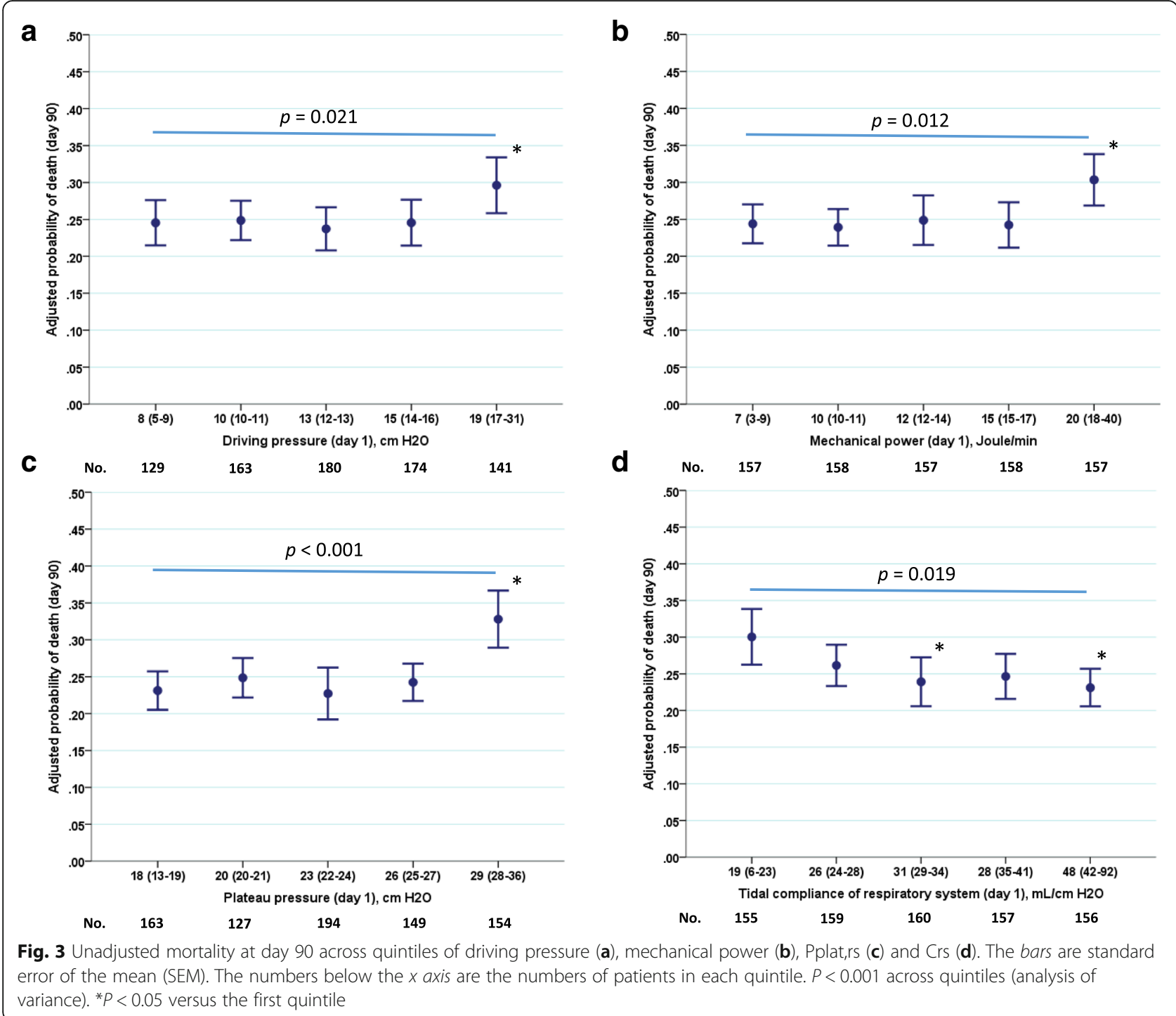

ventilator settings used and the present results were highly significant.

\section{Clinical implications}

The main clinical message from our data is that if $\mathrm{V}_{\mathrm{T}}$ and Pplat,rs are strictly maintained to $6 \mathrm{ml} / \mathrm{kg}$ predicted body weight and below 28-30 $\mathrm{cmH}_{2} \mathrm{O}, \Delta$ Prs shares the same information as Pplat,rs about the association with day 90-mortality. Management of patients with ARDS is an ongoing process that combines physiologic [14] and pragmatic information [17]. The use of $\Delta$ Prs to manage patients as a therapeutic target should be part of the research agenda in ARDS [18]. However, better knowledge of the physiologic meaning of $\Delta \operatorname{Prs}$ is mandatory, to make sure that $\Delta$ Prs is a relevant tool to set the ventilator adequately in ARDS patients, as it has been done for PEEP selection [19-23]. As an example, it has been shown that
$\Delta$ Prs correlates with lung stress and, hence could detect over-distension [24].

\section{Conclusions}

When lung protective mechanical ventilation is applied to patients with ARDS, $\triangle \mathrm{Prs}, \mathrm{Crs}$, and Pplat were risk factors for mortality.

\section{Additional files}

Additional file 1: Table S1. Multivariate Cox regression analysis for factors on day 1 including mechanical power associated with ARDS mortality at day 90. (DOC $33 \mathrm{~kb}$ )

Additional file 2: Table S2. Multivariate Cox regression analysis for factors on day 1 including plateau pressure associated with ARDS mortality at day 90. (DOC $33 \mathrm{~kb}$ )

Additional file 3: Table S3. Multivariate Cox regression analysis for factors on day 1 including compliance of the respiratory system associated with ARDS mortality at day 90. (DOC $33 \mathrm{~kb}$ ) 
Additional file 4: Table S4. Multivariate Cox regression analysis for factors on day 1 including a couple of collinear variables associated with ARDS mortality at day 90. (DOCX $19 \mathrm{~kb}$ )

Additional file 5: Figure S1. Kaplan-Meier graphs of the probability of survival over 90 days after inclusion of patients with ARDS according to Pplat,rs and Crs. The curves were compared by using the log rank test. (PPTX $92 \mathrm{~kb}$ )

Additional file 6: Figure S2. Adjusted probability of survival derived from the Cox model according to $\Delta \operatorname{Prs}(\mathbf{A})$ and mechanical power $(\mathbf{B})$. (PPTX $89 \mathrm{~kb}$ )

Additional file 7: Figure S3. Adjusted probability of survival derived from the Cox model according Pplat,rs (A) and Crs (B). (PPTX 90 kb)

\section{Abbreviations}

Crs: compliance of the respiratory system; FIO2: oxygen fraction in air; HR: hazard ratio; NMBA: neuromuscular blocking agent; PaCO2: artial pressure of carbon dioxide in arterial blood; $\mathrm{PaO} 2$ : partial pressure of oxygen in arterial blood; PEEP: positive end-expiratory pressure; PEEPtot,rs: total peep of the respiratory system; $\mathrm{pH}$ : potential of hydrogen; Pplat,rs: plateau pressure of the respiratory system; SAPS: simplified acute physiology score; SD: standard deviation; SOFA: sequential organ failure assessment; VILI: ventilator-induced lung injury; VT: tidal volume; $\Delta \mathrm{PL}$ : transpulmonary driving pressure; $\Delta \mathrm{Prs}$ : driving pressure of the respiratory system

\section{Acknowledgements}

The authors would like to thank all the clinicians and their team involved in both the Acurasys and Proseva trials.

\section{Funding}

Funding was from PHRC regional 2004 for the Acurasys trial and PHRC national 2006 and 2010 for the Proseva trial from the French ministry of health in France.

\section{Availability of data and materials}

No.

\section{Authors' contributions}

CG had the idea of study and made substantial contributions to conception and design, and drafted the manuscript. LP made substantial contributions to conception and design, and analysis and interpretation of data, and reviewed the manuscript. JR was involved in drafting the manuscript and revising it critically for important intellectual content. LA made substantial contributions to acquisition of data, and analysis and interpretation of data. $\mathrm{AL}$ made substantial contributions to conception and design, acquisition of data, and analysis and interpretation of data. JMF made substantial contributions to conception and design, and analysis and interpretation of data, and reviewed the manuscript. All authors read and approved the final manuscript.

\section{Competing interests}

The authors declare that they have no competing interests.

\section{Consent for publication}

Not applicable.

\section{Ethical approval and consent to participate}

Obtained from the ethics committee of the Marseille University Hospital (Comité Consultatif de Protection des Personnes dans la Recherche Biomédicale) for the Acurasys trial and from Comité Consultatif de Protection des Personnes dans la Recherche Biomedicale Sud-Est IV, Lyon, for the Proseva trial. We had all necessary consent from any patients involved in both the original trials.

\section{Author details}

'Réanimation Médicale Groupement Hospitalier Nord Hospices civils de Lyon, Lyon, France. ${ }^{2}$ Université de Lyon, 1 69100, Villeurbanne, France. ${ }^{3}$ Institut Mondor de Recherche Biomédicale, INSERM 955 Equipe 13, Créteil, France. ${ }^{4}$ Hôpitaux de Marseille Hôpital Nord Réanimation des Détresses
Respiratoires et des Infections Sévères, Marseille 13015, France. ${ }^{5}$ Aix-Marseille University EA 3279 Research Unit Department of Public Health Medecine School University Marseille, Marseille, France. ${ }^{6}$ URMITE UMR CNRS 7278, Marseille 13005, France. ${ }^{7}$ Réanimation Médicale CHU de Nantes, Nantes, France. ${ }^{8}$ Centre de Coordination et de Lutte Contre les Infections Nosocomiales Sud-Est, Saint-Genis Laval, France. ${ }^{9}$ Hôpitaux de Marseille Department of Research and Innovation Support Unit for clinical research and economic evaluation, Marseille 13005, France.

Received: 17 August 2016 Accepted: 2 November 2016

Published online: 29 November 2016

\section{References}

1. ARDSnet. Ventilation with lower tidal volumes as compared with traditional tidal volumes for acute lung injury and the acute respiratory distress syndrome. The Acute Respiratory Distress Syndrome Network. N Engl J Med. 2000;342(18):1301-8.

2. Amato MB, Barbas CS, Medeiros DM, Magaldi RB, Schettino GP, Lorenzi-Filho G, Kairalla RA, Deheinzelin D, Munoz C, Oliveira R, et al. Effect of a protective-ventilation strategy on mortality in the acute respiratory distress syndrome. N Engl J Med. 1998;338(6):347-54.

3. Amato MB, Meade MO, Slutsky AS, Brochard L, Costa EL, Schoenfeld DA Stewart TE, Briel M, Talmor D, Mercat A, et al. Driving pressure and survival in the acute respiratory distress syndrome. N Engl J Med. 2015;372(8):747-55.

4. Papazian L, Forel JM, Gacouin A, Penot-Ragon C, Perrin G, Loundou A, Jaber S, Arnal JM, Perez D, Seghboyan JM, et al. Neuromuscular blockers in early acute respiratory distress syndrome. N Engl J Med. 2010;363(12):1107-16.

5. Guerin C, Reignier J, Richard JC, Beuret P, Gacouin A, Boulain T, Mercier E, Badet M, Mercat A, Baudin O, et al. Prone positioning in severe acute respiratory distress syndrome. N Engl J Med. 2013;368(23):2159-68.

6. Bernard GR, Artigas A, Brigham KL, Carlet J, Falke K, Hudson L, Lamy M, Legall JR, Morris A, Spragg R. The American-European Consensus Conference on ARDS. Definitions, mechanisms, relevant outcomes, and clinical trial coordination. Am J Respir Crit Care Med. 1994;149(3):818-24.

7. Cressoni M, Gotti M, Chiurazzi C, Massari D, Algieri I, Amini M, Cammaroto A, Brioni M, Montaruli C, Nikolla K, et al. Mechanical power and development of ventilator-induced lung injury. Anesthesiology. 2016;124(5):1100-8.

8. Bellani G, Laffey JG, Pham T, Fan E, Brochard L, Esteban A, Gattinoni L, van Haren F, Larsson A, McAuley DF, et al. Epidemiology, patterns of care, and mortality for patients with acute respiratory distress syndrome in intensive care units in 50 countries. JAMA. 2016:315(8):788-800.

9. Villar J, Kacmarek RM. Concerns about LUNG-SAFE: response to the letter to the Editor of Critical Care by Bellani et al. Crit Care. 2016;20:296.

10. Villar J, Schultz MJ, Kacmarek RM. The LUNG SAFE: a biased presentation of the prevalence of ARDS! Crit Care. 2016;20(1):108.

11. Mekontso Dessap A, Boissier F, Charron C, Begot E, Repesse X, Legras A, Brun-Buisson C, Vignon P, Vieillard-Baron A. Acute cor pulmonale during protective ventilation for acute respiratory distress syndrome: prevalence, predictors, and clinical impact. Intensive Care Med. 2016:42(5):862-70.

12. Baedorf Kassis E, Loring SH, Talmor D. Mortality and pulmonary mechanics in relation to respiratory system and transpulmonary driving pressures in ARDS. Intensive Care Med. 2016;42(8):1206-13.

13. Beitler JR, Guerin C, Ayzac L, Mancebo J, Bates DM, Malhotra A, Talmor D. PEEP titration during prone positioning for acute respiratory distress syndrome. Crit Care. 2015;19:436.

14. Gattinoni L, Carlesso E, Santini A. Physiology versus evidence-based guidance for critical care practice. Crit Care. 2015;19 Suppl 3:S7.

15. Cressoni M, Gotti M, Chiurazzi C, Massari D, Algieri I, Amini M, Cammaroto A, Brioni M, Montaruli C, Nikolla K, et al. Mechanical power and development of ventilator-induced lung injury. Anesthesiology. 2016.

16. Gattinoni L, Tonetti T, Cressoni M, Cadringher P, Herrmann $P$, Moerer $O$, Protti A, Gotti M, Chiurazzi C, Carlesso E, et al. Ventilator-related causes of lung injury: the mechanical power. Intensive Care Med. 2016;42(10):1567-75.

17. Gattinoni L, Quintel M. How ARDS should be treated Crit Care. 2016:20:86.

18. Beitler JR, Goligher EC, Schmidt M, Spieth PM, Zanella A, Martin-Loeches I, Calfee CS, Cavalcanti AB. Personalized medicine for ARDS: the 2035 research agenda. Intensive Care Med. 2016;42(5):756-67. 
19. Chiumello D, Cressoni M, Carlesso E, Caspani ML, Marino A, Gallazzi E, Caironi P, Lazzerini M, Moerer O, Quintel M, et al. Bedside selection of positive end-expiratory pressure in mild, moderate, and severe acute respiratory distress syndrome. Crit Care Med. 2014:42(2):252-64.

20. Chiumello D, Cressoni M, Colombo A, Babini G, Brioni M, Crimella F, Lundin S, Stenqvist O, Gattinoni L. The assessment of transpulmonary pressure in mechanically ventilated ARDS patients. Intensive Care Med. 2014;40(11):1670-8.

21. Chiumello D, Guerin C. Understanding the setting of PEEP from esophageal pressure in patients with ARDS. Intensive Care Med. 2015.

22. Chiumello D, Marino A, Brioni M, Cigada I, Menga F, Colombo A, Crimella F, Algieri I, Cressoni M, Carlesso E, et al. Lung recruitment assessed by respiratory mechanics and computed tomography in patients with acute respiratory distress syndrome. What is the relationship? Am J Respir Crit Care Med. 2016:193(11):1254-63.

23. Cressoni M, Chiumello D, Carlesso E, Chiurazzi C, Amini M, Brioni M, Cadringher P, Quintel M, Gattinoni L. Compressive forces and computed tomography-derived positive end-expiratory pressure in acute respiratory distress syndrome. Anesthesiology. 2014;121(3):572-81.

24. Chiumello D, Carlesso E, Brioni M, Cressoni M. Airway driving pressure and lung stress in ARDS patients. Crit Care. 2016;20:276.

\section{Submit your next manuscript to BioMed Central} and we will help you at every step:

- We accept pre-submission inquiries

- Our selector tool helps you to find the most relevant journal

- We provide round the clock customer support

- Convenient online submission

- Thorough peer review

- Inclusion in PubMed and all major indexing services

- Maximum visibility for your research

Submit your manuscript at www.biomedcentral.com/submit 